2019 Global Fashion Management Conference at Paris Proceedings: 812-818 (July 2019) https://doi.org/10.15444/GFMC2019.08.04

\title{
STORYMAKING: AN INVESTIGATION ON THE PROCESS OF CO- CREATED BRAND STORYTELLING IN THE SPORTING GOODS INDUSTRY
}

Daniela Langaro, Instituto Universitário de Lisboa (ISCTE-IUL), Business Research Unit (BRU-IUL), Portugal

Charlotte Hackenberger, Instituto Universitário de Lisboa (ISCTE-IUL), Portugal

Sandra Maria Correia Loureiro, Instituto Universitário de Lisboa (ISCTE-IUL), Business Research Unit (BRU-IUL), Portugal ${ }^{1}$

\begin{abstract}
Introduction

Brand storymaking is the new, evolving buzzword in marketing and branding practice. The current study explores the evolving concept of brand storymaking as a highly relevant future branding and communications tool for the sporting goods industry (SGI). In response to increasing consumer involvement, the term of brand storymaking refers to brand storytelling in the context of co-creation. In recent years, brand storytelling has become an important content creative strategy in communications (Woodside, 2010; Lundqvist et al., 2013; Singh \& Sonnenburg, 2012), with brands being promoted by means of stories which are created and distributed by marketers, in a one-to-many traditional approach (e.g. advertising campaigns).
\end{abstract}

Storymaking has evolved from this practice with brands' audience integrating the content creation process as storytellers. In contrast to storytelling which is broadcast mindset driven, storymaking allows a two-way participatory approach, leveraged by social media platforms and new technologies (Berkowitz, 2014; Coleman, 2012; Kanarick, 2014; Gensler et al., 2013). This development goes along with the current evolution of marketing communications from a transactional to a personalized, customer-oriented and technology-driven relationship marketing approach (Kitchen et al., 2004; Hughes \& Fill, 2007). In this perspective, co-creating content with brand customers emerges as a strategy to drive more valuable and involving stories than ever before, which is especially relevant for the highly competitive SGI, where emotional involvement around athletes is crucial, and brand storymaking can become a gamechanger.

Despite the high relevance and prominence of its underlying principles - brand storytelling and co-creation - little is found in academic literature on brand storymaking or co-created storytelling. Facing a widely undiscovered topic in academic research, the current study deals with the research question on how the sports brand storymaking process in social media can be defined in an ideal way.

In order to address this question, literature review and practice, in cooperation with a global sporting goods company, are combined with the objective of proposing an exemplary process model for SGIs brand storymaking in social media, which is capable to integrate the story consistently into the brand, so the stories are accepted as expressions of the brand (Fog et al., 2010).

\footnotetext{
${ }^{1}$ sandramloureiro@netcabo.pt
} 
With the aim of addressing the research question on how can SGIs brand storymaking process in social media be defined in an ideal way, the following objectives were persecuted: $i$ ) to validate a process model which captures current brand storymaking practices in social media (preliminary process model); ii) to suggest improvements to the current process model.

\section{Literature Review}

Technological advancements allow firms to approach consumers in a more direct, personalized and interactive way than ever before, involving the audience actively in the making of a story. Within that, social media plays a major role in brand storymaking, empowering consumers to participate. In the overall marketing context, brand storymaking can be classified as a branding and communications tool with the purpose to co-create engaging brand stories with internal and external audiences, that benefits brand equity.

The literature review shows that little research is available on brand storymaking and its process. The improvisation (improv) theatre approach introduced by Singh and Sonnenburg (2012), combined with the pinball metaphor of Hennig-Thurau et al. (2010), was found to be most appropriate to describe the new phenomenon's process and serve as a reference framework for empirical research. Singh and Sonnenburgm (2012) introduced the metaphor of improvisation theatre to reflect the process of cocreated storytelling in social media. Their research compares the abstract phenomenon of brand stories in social media with the more concrete field of improv theatre. This comparison is possible because brands and users in social media interact in the same way that is characteristic for improv theatre. Set in with branding, Singh \& Sonnenburg (2012) state the brand as the star of the performance, brand owner and consumers as supporting players and the brand story as the play script. In social media, the roles of narrator and listener are blurring, because the brand owner and the consumer can play both roles resulting in an interactive, co-created brand story. They conceptualize brand co-created storytelling in social media as an on-going and collaborative process - the brand narrative - co-created by interrelated content or stories. The pinball metaphor of Hennig-Thurau et al. (2010) reflects the process of co-created storytelling in social media with unpredictable, uncontrolled interactions and new media effects. Figure 1 presents the theoretical model resulting from the combined approach.

\section{Methodology}

Given the objectives proposed and the novelty of the topic an exploratory inductive approach with case study research methodology was chosen. An embedded single-case study with two units of analysis (the two most relevant business units of the company) was conducted. Due to the extensive size of the company (one of global market leaders in SGI), the two business units operate independently, allowing that the analysis of results would be enriched with more variety.

Following Bonoma (1985), the case study research was conducted in four stages of inductive knowledge development, including drifting, designing, predicting and the disconfirmation stage. The method of analysis is qualitative research in a two-fold approach based on the theories of Schreier (2014) and Mayring (2015). Firstly, a qualitative web Content Analysis (CA) of social media was conducted with the objective to capture current practices and critically assess the theoretical model (as in Figure 1) aiming to develop a preliminary process model design (Figure 1). For the 
analysis of results, a coding frame was created and refined throughout the process of trial coding and main analysis to allow for segmentation into specific coding units. Secondly, data was gathered through in-depth expert interviews aiming to evaluate the tentative generalizations, gathered in the first stage, regarding their predictive power and parameters and further improve the preliminary process model. This involved the formulation of an interview guide, the selection of appropriate experts in marketing communications and the collection of data across nine interviews, each over the duration of 60 to 90 minutes. The summative, inductive analysis of collected interview data was structured in context categories for a meaningful interpretation of findings. For the sake of feasibility, several limitations have been determined in advance to narrow down the scope of the study: $i$ ) only brand owner campaign posts on Facebook, ii) for the two most relevant business units and iii) in a limited timeframe were selected for analysis. Further audiences besides consumers (e.g. investors or employees) were not considered. To ensure reliability and validity across both CA steps, the data has been tested on consistency and high quality, complemented by individual validation steps, with triangulation of data involving primary and secondary sources.

\section{Results}

For the qualitative web CA of social media, the characteristics of brand owner generated campaign posts were reviewed with the objective to detect process patterns of interactions with consumers. The social media analysis shows that the theoretical model (as in Figure 1) captures well the current process dynamics.

The CA of expert interviews complements the results of social media analysis. The analysis of interviews reveal that despite the preliminary process (as in Figure 1) captures well the current dynamics, it is of limited interest for the future development of storymaking processes as it does not accommodate critical aspects raised by interviewees.

Based on the findings from in-depth interviews, experts evaluated the improv theatre approach combined with the pinball metaphor, as a valid theoretical model for the brand storymaking process in social media, in general. However, three critical changes to the preliminary model were proposed, namely: (i) to provide a strong, compelling and credible trigger to consumers initiating participation, (ii) to provide a platform where consumers can co-create the story with the brand (iii) to provide a toolkit for consumers to ease their participation in the process. Based on the findings, improvements to the preliminary model were implemented with final model being proposed (as in Figure 2). Hereby, a multitude of functionalities and characteristics have been added to the preliminary model. Among the most important are the introduction of fluent campaign phases (preparation/ brand/ interaction phase) and reactive action steps, brand positioning and objectives, as well as real-time monitoring with controlling filters and regular check-ins on strategy and brand design. Moreover, the extension to further platforms (asset/ consumer/ influencer platform) with hashtags as connectors linking the brand to individual content was introduced. As a highly relevant extension to the final process model, the segmentation of consumers (selection vs. entity of consumers) with direct implications on the brand storymaking approach was integrated. Besides, a collection of general observations (e.g. dealing with negative consumer voices) serve as valuable insights to leverage brand storymaking as a tool. 


\section{Conclusions, Implications and Limitations}

The current study explores the evolving concept of brand storymaking as a highly relevant future branding and communications tool for the sporting goods industry (SGI). Literature review and practice, in cooperation with a global sporting goods company, are combined with the objective of proposing an exemplary process model for SGIs brand storymaking in social media.

A final process model is proposed (as in Figure 2). The study has many implications for theory and practice. Regarding theory, the model proposed may guide future studies on the main phases, preparation required and dynamics of relations occurring while storymaking evolves. For managers, the process model proposed suggests a sequence of action steps that companies can effectively make use in order to share their own stories in joint collaboration endeavors.

Inherent limitations are present (e.g. single company and stakeholders considered), which may suggest that future studies further validate the findings within larger samples and extended scope of industries and stakeholders.

Keywords: brand storymaking, co-creation, sporting goods industry, case study

Acknowledge: This work was supported by Fundação para a Ciência e a Tecnologia, grant UID/GES/00315/2019

\section{References}

Berkowitz, D. (2014). The Beginning of the End of Storytelling. Retrieved October 20, 2016, from AdvertisingAge: http://adage.com/article/digitalnext/beginningend-storytelling/294975/

Bonoma, T. V. (1985). Case Research in Marketing: Opportunities, Problems, and a Process. Journal of Marketing Research, 22 (2), 199-208.

Coleman, J. (2012). Fast Company - Leadership. Retrieved January 2, 2017, from https://www.fastcompany.com/1826645/why-collaborative-storytelling-futuremarketing

Daugherty, T., Eastin, M., \& Bright, L. (2008). Exploring consumer motivations for creating user-generated content. Journal of Interactive Advertising, 8(2), 1-24.

Fog, K., Budtz, C., Munch, P., \& Blanchette, S. (2010). Storytelling - Branding in Practice (Vol. 2nd edition). Berlin: Springer Verlag.

Gensler, S., Völckner, F., Liu-Thompkins, Y., \& Wiertz, C. (2013). Managing Brands in the Social Media Environment. Journal of Interactive Marketing, 27, 242256.

Hennig-Thurau, T., Malthouse, E., Friege, C., Gensler, S., Lobschat, L., Rangaswamy, A., \& Skiera, B. (2010). The Impact of New Media on Customer Relationships. Journal of Service Research, 13(3), 310-330.

Hughes, G., \& Fill, C. (2007). Redefining the nature and format of the marketing communications mix. The Marketing Review, 7(1), 45-47.

Ind, N., Iglesias, O., \& Schultz, M. (2013). Building Brands Together: Emergence and Outcomes of Co-Creation. California Management Review, 55(3), 5-26

Kanarick, B. (2014). Wired - Insights. Retrieved January 2, 2017, from https://www.wired.com/insights/2014/10/digital-innovation-golden-age/ 
Kitchen, P. J., Brignell, J., Li, T., \& Spickett Jones, G. (2004). The Emergence Of IMC: A Theoretical Perspective. Journal of Advertising Research, 44(1), 1930.

Labrecque, L., vor dem Esche, J., Mathwick, C., \& P., T. (2013). Consumer Power: Evolution in the Digital Age. Journal of Interactive Marketing, 27(4), 257-69.

Lundqvist, A., Liljander, V., Gummerus, J., \& van Riel, A. (2013). The impact of storytelling on the consumer brand experience: The case of a firm-originated story. Journal of Brand Management, 20 (4), 283-297.

Mayring, P. (2015). Qualitative Inhaltsanalyse (12 ed.). Weinheim: Beltz.

Phelps, J. E., Lewis, R., Mobilio, L., Perry, D., \& Raman, N. (2004). Viral Marketing or Electronic Word-of-Mouth Advertising: Examining Consumer Responses and Motivations to Pass Along Email. Journal of Advertising Research, 44(4), 333-348.

Schau, H., \& Gilly, M. (2003). We Are What We Post? Self-Presentation in Personal Web Space. Journal of Consumer Research, 30(3), 385-404.

Schreier, M. (2014). Qualitative Content Analysis. In U. Flick, The SAGE Handbook of Qualitative Data Analysis (pp. 170-183). London: Sage Publications.

Singh, S., \& Sonnenburg, S. (2012). Brand performances in social media. Journal of Interactive Marketing, 26, 189-197.

Woodside, A. G. (2010). Brand-Consumer Storytelling Theory and Research: Introduction to a Psychology \& Marketing Special Issue. Psychology \& Marketing, 27(6), 531-540. 


\section{Global Fashion Management Conference at Paris}

Figure 1: Theoretical model for Storymaking (co-created storytelling) process in social media

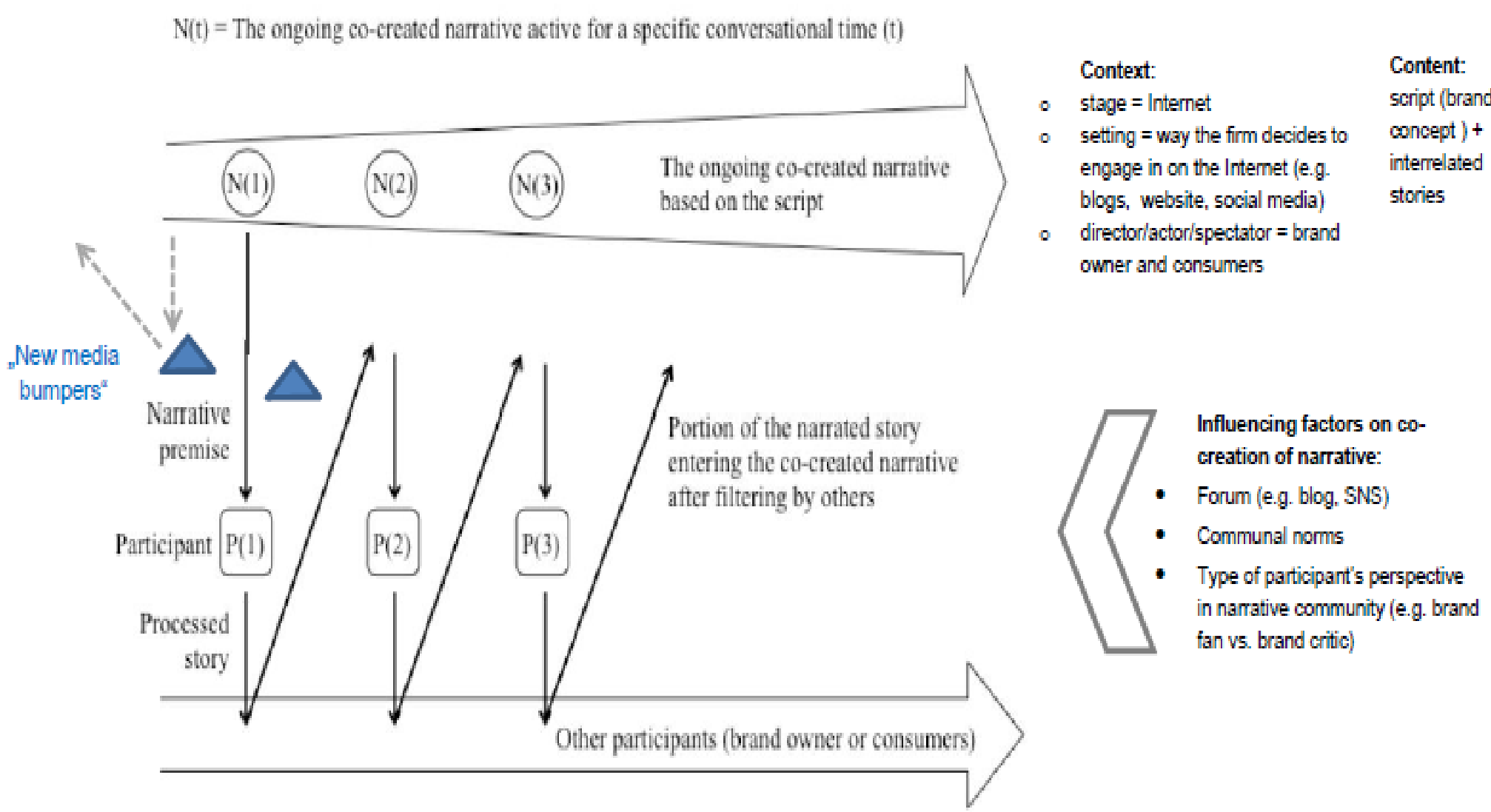

Conversational time 
Figure 2: Proposed process model for SGI brand Storymaking in social media

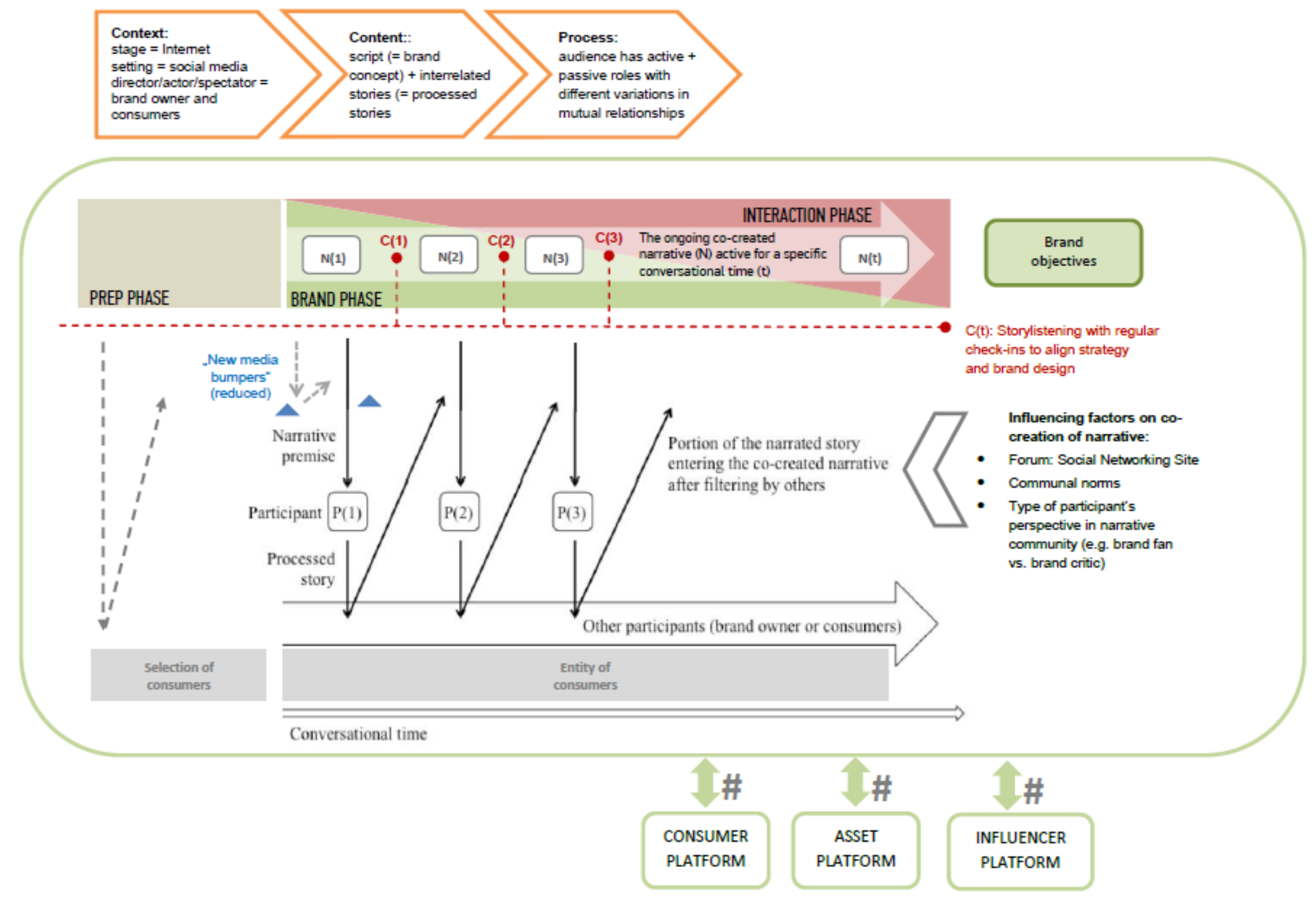

